\title{
Palma, forjador de la identidad cultural iqueña
}

\author{
José Vásquez Peña \\ Instituto Ricardo Palma de la Universidad Ricardo Palma \\ Investigador independiente \\ jocavape16@hotmail.com
}

\section{Resumen}

El presente trabajo ilustra en qué medida la obra palmista, ambientada en Ica, ha venido gestando, con el transcurso del tiempo, la iqueñidad como sentimiento y pasión por el terruño.

Se establece cómo este proceso identitario que se inicia en las primeras décadas del siglo XX, paralelamente a la forja de la peruanidad, objetivo supremo de Palma, logra el nacimiento y fortalecimiento de la iqueñidad, que en la hora actual se expresa en una eclosión formidable de elementos que permiten verificar que la gestión cultural, que la creación artística, que la gestión educativa, etc. se han asociado al impostergable fortalecimiento de la identidad cultural iqueña.

Palabras clave: Identitario, iqueñidad, identidad cultural, gestión cultural, pertenencia, anclaje, herencia palmista.

\section{Abstract}

This work illustrates the extent to which the work of Ricardo Palma, set in Ica, has been developing, over the course of time, the iqueñidad as a feeling and passion for the terroir.

It is established how this identity process that begins in the first decades of the 20th century, parallel to the forging of Peruvianness, the supreme objective of Palma, achieves the birth and strengthening of the iqueñidad, which in the current time is expressed in a formidable explosion of elements that allow to verify that the cultural management, the artistic creation, the educational management, and others have associated themselves with the urgent need to strengthen Ica's cultural identity.

Keywords: Identity, iqueñidad, cultural identity, cultural management, belonging, anchorage, palmist inheritance. 
José Vásquez Peña, Abogado, Profesor, estudios culminados de Maestría en Educación; Escritor, poeta, ensayista, conferencista, investigador. Es miembro correspondiente del Instituto Ricardo Palma. Ha publicado: El Parral de las Ánimas, La soledad del viejo huarango, Antología de la poesía infantil del siglo XX (co-autor), Valdelomar para niños y jóvenes (co-autor), El increíble viaje al país de Duna Encantada. Las Huellas del Hipocampo de Oro. Tiene culminadas las siguientes obras: La mirilla del tiempo, Mundo mago, la Tortura de lo imposible, Las princesas encantadas del país de las Dunas, Verdadera historia de los Peñahuarango, La prodigiosa corte del dios Kon, Viaje hacia la realidad, El hombre que se entretenía capturando el tiempo. 


\section{Prolegómeno sobre identidad e identidad cultural}

Pertenencia. ¿Difícil cuestión en el plano creativo? Aquel sentimiento de arraigo telúrico que aflora, a manera de estigma, en el habitante de un lugar (o para ir entrando en materia: en la obra de un escritor) condensa su identificación con el terruño. Orientación que es trasmitida a sus lectores, generando por efecto multiplicador eficaz un desarrollo de ese sentimiento. Este fenómeno solo es explicable si acudimos a un enfoque identitario.

Concebimos la identidad como un sentido de pertenencia que nos liga a colectivos; y asimismo, nos permite asumir la diferenciación de otros. Es, en síntesis, la expresión pragmática de la oposición unidad/otredad, tan común, pero tan difícil de entender. Recuerdo que cierta vez leí la siguiente frase de "Sin otredad no hay unidad. Y más, la otredad es la manifestación de la unidad, la manera en que esta se despliega" (Paz Octavio, 1984: sección El arco y la lira). Y comprendí que el uno y el otro están inmersos en un sistema relacional que se denomina identidad cultural, formada por un conjunto de valores, tradiciones, símbolos, creencias y modos de comportamiento que funcionan como elementos dentro de un grupo social. La interrelación establecida genera un sentimiento de pertenencia que nos orienta a calificarnos y decir: soy peruano; o en menor amplitud: soy iqueño. Es decir, se produce ese acto de compartir un pasado y un proyecto de futuro, nos identifica y nos hace partícipes de la historia, la cultura, las formas de vida, los usos, las costumbres de un determinado lugar.

Al respecto, Kymlicka (1996: 129) afirma: "La identidad cultural proporciona un anclaje para la auto identificación [de las personas] y la seguridad de una pertenencia estable sin tener que realizar ningún esfuerzo". 
Nuestro ensayo plantea cómo a través de las Tradiciones Peruanas se ha ido gestando, dentro del sentimiento de peruanidad, la identidad cultural iqueña. Aseveramos que esta se encuentra aún en proceso de fortalecimiento; sin embargo, hemos rastreado el efecto producido y validamos la gran influencia ejercida por la obra palmista en este propósito.

\section{Las tradiciones forjan el carácter identitario de la comunidad}

Si nos atenemos a la referencia histórica siguiente: "Don Ricardo Palma escribió sus primeras tradiciones peruanas entre 1870 y 1879" (Hijar, 2015: 249) y al hecho que su lectura se generalizó, desde ese entonces y durante todo el siglo XX en la escuela pública del Perú, tenemos que aceptar que el proceso de forja de peruanidad fue in crescendo a la par de la aparición de un sentimiento de menor envergadura en cada lugar sobre cuyas situaciones (históricas, costumbristas, etc.) escribió Palma.

En lo que atañe a la construcción de este sentimiento en Ica, que calificamos como iqueñidad, desprendido -como queda establecido- de la percepción general de peruanidad, se gestó en los siguientes niveles:

\subsection{La forja escolarizada de la iqueñidad}

A partir de la lectura de las Tradiciones Peruanas en las escuelas iqueñas, gradualmente se concienció, tiempo mediante, a los alumnos, entregándoles conocimientos históricos, costumbres, idiosincrasia, de nuestro colectivo social.

Por ejemplo, cuando se lee la tradición La Achirana de Inca nos invade una rara sensación de familiaridad, a pesar que el 
espacio narrativo está referido a otro tiempo: al momento en que llegaron los incas por estas tierras. Leamos:

En 1412, el Inca Pachacutec, acompañado de su hijo el príncipe imperial Yupanqui y su hermano Capac Yupanqui, emprendió la conquista del valle de Ica, cuyos habitantes, si bien de índole pacífica, no carecían de esfuerzo y elementos para la guerra. Comprendiéndolo así el sagaz monarca, y antes de recurrir a las armas propuso a los iqueños que se sometieran a su paternal gobierno. Aviniéronse estos de buen grado y el inca y sus cuarenta mil guerreros fueron cordial espléndidamente recibidos por los naturales. (Palma, 1964: 8).

Esta tradición evidencia un momento crucial de la historia de Ica: la llegada de los incas. Refleja la calidad humana con que asumieron nuestros antepasados ese acontecimiento, pero nos ilustra, también, sobre la historia y costumbres de Ica, sus carencias, verbigracia: la escasez de agua y la forma como, según la tradición, se resolvió. Denota igualmente que los iqueños de esa remota época no carecían de esfuerzo y elementos para la guerra, sin embargo, supieron privilegiar el diálogo frente a la violencia. En ese sentido, Palma entrega un mensaje de paz que no siempre acompañó a los iqueños, quienes en épicas jornadas, como en las etapas históricas de la Guerra de la Independencia y la Guerra con Chile, sacaron a relucir la valentía y su espíritu contestatario y de oposición a la invasión.

La lectura permanente de las tradiciones en los colegios durante todo el siglo XX y parte del siglo XXI que llevamos recorrido, ha generado un sentimiento de apego a la tierra. Esto se comprenderá mejor si revisamos, hoy, el plan lector de la Región y comprobamos que las tradiciones palmistas, sobre todo la comentada, se encuentran en él. 
A través del tiempo, se ha ido formando conciencia sobre la necesidad de fortalecer la identidad iqueña, viéndose en la actualidad resultados pragmáticos, como el siguiente: el distrito de Pachacutec, fundado en 1964, ha remodelado su plaza de armas, en marzo del 2013, convirtiéndola en un parque temático en el cual se grafica la tradición La Achirana del Inca.

Lo mismo sucede con otras tradiciones que sobre Ica escribiera Palma. Las brujas de Ica, la segunda más consultada de las once escritas, le ha dado a nuestra tierra un atractivo turístico más, por ese aire de misterio que le imprimió Palma a ese lugar. Notamos ese rasgo enigmático en el siguiente párrafo de esa tradición:

En cuanto a Ica, consta en uno de los números de El Imparcial, periódico que en 1873 se publicaba en esa ciudad, que una pobre mujer de Pueblo Nuevo fue atada a un árbol por un hombre, el que le aplicó una terrible azotaina en castigo de haberlo maleficiado. Cosa idéntica se había realizado en 1860 con Jesús Valle, negra octogenaria y esclava de los antiguos marqueses de Campoameno, a la que costó gran trabajo impedir que los peones de una hacienda la convirtieran en tostón. (Palma, 1964: 268)

El caserío de Cachiche ha alcanzado, a través de los años, un notable desarrollo y se mantiene en el imaginario popular de los habitantes y de los turistas. Es atracción por lo sobrenatural, tanto así que desde hace algunos años, al ingreso de este lugar incrustado en una rama de un copioso huarango, existe una escultura hecha por el escultor iqueño Luis Peña y Peña que se ha convertido en el sitio más visitado, y allí encontramos a los niños guías del lugar que precisamente narran las situaciones mágicas del lugar con bastante sobriedad, acudiendo a la tradición Las Brujas de Ica. 
Una referencia más, desprendida del párrafo citado: se menciona allí a los marqueses de Campoameno, de quienes se dice más en la tradición El que más vale no vale tanto como Valle vale.

Era don Alonso González del Valle no solo notable por su título y fortuna, sino también por su talento. Dice la tradición que escribió muy buenos versos y que, como abogado lució sus dotes. (Palma, 1964: 595)

La casona del Marqués de Campoameno está ubicada en el centro de la ciudad de Ica, esquina de las calles Lima y Cajamarca, en la misma Plaza de Armas. La menciono porque es expresión del sentimiento de iqueñidad. En la actualidad viene siendo restaurada, así como se mantiene conservado el frontis de otra casona colonial que se menciona en la tradición que hemos citado.

El que más vale no vale tanto como Valle vale (...) Tal era el mote que en su escudo de armas lucía el señor don Alonso Gonzales del Valle, primer marqués de Campoameno y el más acaudalado de Ica, sin excluir ni al señor de Apezteguía, primer marqués de Torrehermosa. (Palma, 1964: 594)

Esa antigua casona, ubicada en la Plaza de Armas, sirve hoy de sede del Banco Continental, conservándose solo el frontis, de rasgos arquitectónicos coloniales.

Lo expresado hasta aquí demuestra cómo con el tiempo la obra de Palma ha ido cincelando en el iqueño un sentimiento de arraigo.

Ampliamos el sustento de nuestra tesis acudiendo a lo señalado por el poeta Manuel Pantigoso, sobre la importancia de la obra de Palma, en su discurso de incorporación al Instituto Ricardo Palma 1998-1999: 
Por eso es capaz de revalorar la esencia de una continuidad en el tiempo, eterno y sintético. Al mirarnos en esa obra, en esa poesía, en esas tradiciones, tenemos una mejor conciencia de nuestra esencial peruanidad. A cuya sentencia, dice Cabel: Yo agregaría de nuestra esencial iqueñidad. (Cabel, 2008: 12).

\subsection{La continuidad de la herencia palmista}

Palma abordó, desde el inicio de su obra de tradicionista, el propósito de formar peruanidad. En esa perspectiva es el principio y el mayor sustento de una iqueñidad que ya se respira en nuestro medio, aunque con relativa debilidad en la ciudadanía, pero con gran fortaleza en el plano cultural iqueño, como quedará evidenciado líneas abajo.

Incuestionablemente, existe un hilo conductor entre las tradiciones palmistas, en lo pertinente a la construcción de iqueñidad, y los artistas iqueños que a través de sus obras han apostado por este propósito.

Hagamos un breve recuento de obras y autores que, conscientes de la necesidad de reforzar esa tarea y de haber sido tocados por el espíritu palmista de desarrollar el sentimiento de pertenencia a nuestra tierra, se han entregado a la continuación insoslayable de este quehacer.

Mencionamos los principales hitos:

\subsubsection{El rastro palmista en Valdelomar}

Abraham Valdelomar (1888-1919) nace cincuenta y cinco años después de Ricardo Palma (1833-1919). De suerte que la influencia palmista, en lo tocante a la peruanidad, se tradujo en el acendrado amor que le tenía el Conde de Lemos a su tierra. 
Imbuido por ese sentimiento, dice en uno de sus discursos que ofreció el año 1919 en el Teatro Piccone de Ica:

Nada podía ser más grato a mi espíritu, al presentarme en esta tierra de mi nacimiento, a este paraíso de mi infancia, a este poema evocador de mi juventud, a esta realidad dulce de mi vida, a este espíritu de mi arte que es Ica, (SilvaSantisteban, 2001: 243.)

Si se revisan sus conferencias, se encontrará que en gran parte de ellos trasunta ese sentimiento. Enfatizamos: Valdelomar es uno de los grandes jalones en la gesta de iqueñidad. Agregamos a ello que dentro de sus proyectos truncos existía la creación de una revista con el nombre de Patria. En la praxis con sus viajes por el territorio peruano, demostró que era un convencido de generar peruanidad.

En sus obras se aprecia iqueñidad, esencialmente, en su novela corta Yerba Santa y en su obra teatral Verdolaga. De otro lado, afirmamos que en sus conferencias y en casi toda su obra narrativa está presente el sentimiento terrígeno.

\subsubsection{Juan Donaire Vizarreta, Venero de iqueñidad}

Lo hemos sostenido en otros ensayos: el principal manantial del que fluye nuestro sentimiento de iqueñidad se halla en la obra del tradicionista iqueño Juan Donaire Vizarreta. Tanto en Campiña Iqueña, Aspectos folklóricos (1941) como en Leyendas y Tradiciones Iqueñas (1985) se trasluce el propósito, siguiendo a Palma en su apostolado de peruanidad, de forjar la identidad cultural iqueña.

\subsubsection{Las tradiciones urbanas de Gilberto Vásquez Angulo}

En el breve pero valioso texto Las pampas de Hanan y Santa Ana (Vásquez Angulo, 1989) hallamos un conjunto de tradiciones 
que reflejan la vida de Ica. En lo que se refiere a la pampa de Hanan, en su época colonial, anotamos solo los títulos: La viuda. Carretón de Ánimas. Aparición del diablo y Padre salía a la pampa. Y en lo concerniente a la pampa de Santa Ana, las tradiciones aluden a las primeras décadas del siglo XX; en ese sentido, citamos las siguientes: Jaranas de ocho días. La Petacú durmió acompañando un muerto. La suerte china. Baños en el río y Plaza de la estación.

Pampas de Hanan y Santa Ana eran los nombres en el pasado de las actuales plazuelas Barranca y Bolognesi, respectivamente. Las historias contadas encierran un profundo acervo cultural y enlazan al lector con ese sentido de pertenencia a la tierra.

Vásquez Angulo, periodista y autor del libro Historia del deporte iqueño, trabajó muchos años en la Voz de Ica. Es un narrador ameno, cuidadoso e imaginativo, que ha rescatado las tradiciones urbanas iqueñas, haciendo una valiosa labor en el plano de formación del sentimiento de iqueñidad.

\subsubsection{El universo gráfico de las estampas iqueñas}

La obra de Víctor Pacheco Cabezudo (1912-2002), escultor, pintor, dibujante, promotor cultural, nos muestra la secuencia histórica de nuestra tierra. A mi modo de ver, solo este legado (sin dejar de meritar la totalidad de su obra) es grandioso porque permite dar un paseo por la historia de Ica, reconstruyéndola. No olvidemos que la obra artística es esencialmente creación y reconstrucción de realidades.

Incursionemos, señalando los títulos de algunas estampas, en ese mundo polivalente para conocer la historia, la idiosincrasia, las costumbres, el paisaje, de la Ica de todos los tiempos. He aquí un pequeño listado: El Inca y sus súbditos construyendo la Achirana 
(basada en la Tradición palmista: La Achirana del Inca), Fundación española de Ica (1563), Las casonas de la Ica colonial (diversos dibujos), Estampas relativas al momento de la Independencia, Estampas alusivas a los primeros años de la República, Estampas que señalan costumbres y tradiciones iqueñas, Fray Ramón Rojas fajando Cerro Prieto, El tren Ica Pisco y Personajes pintorescos de Ica, entre otras.

Pacheco Cabezudo, creador multifacético, ha historiado, a través de sus Estampas Iqueñas, algo más de mil dibujos a tinta china, el derrotero seguido por el hombre iqueño, para generar cultura y ha aportado grandemente -siguiendo la línea palmista- en la construcción de iqueñidad. Nos ha ayudado a generar $y / o$ fortalecer nuestra identidad cultural iqueña, nuestro sentimiento y nuestra pasión de iqueñidad.

\subsubsection{Poemas cardinales de iqueñidad}

Tal vez Ica sea la región que tienen en su haber una considerable cantidad de poemas que encierran un contenido telúrico. Entiendo que los poetas iqueños y foráneos, le cantan a Ica, inspirados en la herencia palmista en cuanto al cultivo del amor a la tierra que nos/les vio nacer. Anoto algunos títulos: Cantos Nazca de Antonio Maurial; Canto a Ica de Joel Muñoz; Fiesta del Huarango o del árbol en la vendimia de Jesús Cabel; Ica homenaje esencial de Augusto Escalante; Canto a Ica, Ica Surges e Ica, de Miguel Sevillano Díaz; Nazca, de Manuel Pantigoso; El Gran Curaca de José Hidalgo; Ica Telúrica de Augusto Rojas Gasco; y El canto eterno del curaca, de José Vásquez Peña. En esa misma línea, le han cantado a Ica, Orfelinda Herrera de Ángeles y Gerardo Pérez Fuentes.

\subsubsection{Ica en tus manos, la gran enciclopedia de Ica}

La tesonera labor del escritor, historiador y periodista Rodolfo Chalco Cueto ha fructificado luego de largos años de investigación. La publicación de Ica en tus manos, de su autoría, 
una voluminosa enciclopedia de más de ochocientas páginas, conteniendo información variopinta sobre Ica: historia, personajes, música, gastronomía y otras temáticas, ha significado el hito más importante en la formación de iqueñidad.

En sus páginas se puede encontrar, en versión ampliada, lo que ya se entregaba en su anterior libro Historia de Ica: información de lo más importante ocurrido en Ica, a través de los siglos: los asoladores terremotos, las devastadoras inundaciones, los dramáticos acontecimientos bélicos, los despiadados incendios de pueblos enteros y los crímenes que causaron conmoción. También se encontrará la historia de los templosy de los hospitales de Ica, la biografía de los grandes personajes y el aniversario de creación de las instituciones educativas, deportivas, sociales, culturales, políticas y comerciales. Igualmente, la creación política de Ica y sus distritos, las festividades, la gastronomía, los atractivos turísticos y el significado de los vocablos comunes, entre ellos la palabra Ica. Este libro cumple importante función en la formación de la iqueñidad.

\section{Gestión cultural e iqueñidad}

Un concierto de instituciones culturales (incluidas las literarias) y medios de comunicación (radios, televisoras, periódicos, revistas, medios virtuales) han aparecido en estos tiempos en Ica y vienen ampliando de manera admirable el panorama cultural iqueño.

Mencionamos algunos de ellos porque no es nuestro propósito estudiarlos sino señalarlos como expresión del auge de la gestión o el apoyo que le brindan a la iqueñidad. Sostengo que este fenómeno se debe a la toma de conciencia en torno al rol que les compete y esta concienciación se debe inocultablemente al avance de la necesidad de sacar adelante el fortalecimiento del sentimiento de apego al terruño, para que este vaya acorde con el desarrollo económico de la región. 
A manera de recuento, apuntamos los principales exponentes de este quehacer de difusión de la iqueñidad y que según nuestra propuesta obedece en principal medida a la labor de forjador de la identidad cultural iqueña que ha cumplido Ricardo Palma, a través de su obra y de la continuidad que han ejercido sus continuadores imbuidos de esa mística, conforme lo hemos sostenido.

- Instituciones Culturales: Han cumplido ese papel el Patronato de Ica y la Biblioteca Abraham Valdelomar, bajo la dirección del escritor Alberto Benavides Ganoza, contando con la participación del poeta César Panduro Astorga. Ambos lideran en gestión y difusión cultural el propósito de fortalecer la iqueñidad. La mención de algunos de sus logros testimonian esa tarea: publicación masiva de libros iqueños, nacionales e internacionales, organización de eventos culturales de dimensión nacional, creación de Amauta Radio, la radio cultural de Ica, en asociación con Radio Filarmonía de Lima. Otras: la Asociación Iqueñistas, historia y tradición y el Ministerio de Cultura/Dirección desconcentrada de cultura Ica, que mantiene con regularidad los Jueves Culturales, bajo la valiosa promoción del hombre de teatro: Arnaldo Loayza Velásquez.

- Instituciones Literarias. La Asociación Regional de poetas y Artistas (ARPE-ICA) que preside el poeta Miguel Ángel Sevillano Díazy la Asociación Nacional de Escritores y Artistas, presidida por el artista plástico: Óscar Paucas Beramendi.

\section{Medios de comunicación:}

- Periódicos como la Voz de Ica, que desde el año de su aparición (1918) asumió la defensa de la iqueñidad hasta el día de su desaparición física. Ahora, continúa con esa labor en el plano virtual donde aún se mantiene. El diario La Opinión, 
fundado en 1923, vigente aún, cumple descollante gestión en el proyecto de iqueñidad.

Este balance en torno a la fortaleza que ha adquirido el sentimiento de arraigo a Ica, nos lleva a dar una mirada a otros medio de comunicación.

- Programas culturales, radiales y televisivos. En un lugar preponderante encontramos al espacio Ica a través del tiempo que dirige el destacado escritor y periodista Rodolfo Chalco Cueto. Se difunde todos los domingos durante tres horas (de 10 a.m. a 1 p.m.) por Amauta Radio, "Canelo Tv". Un podcast que se transmite en Facebook y destaca en este campo.

- Revistas culturales. En esa misma dirección de generar iqueñidad, citamos a Horizontes Culturales, que lidera César Pacheco Aquije, y Duna Encantada, revistas que salieron en la década de los ochenta del siglo pasado y se mantienen en la brega.

- Medios virtuales. Finalmente, en esta síntesis mencionamos los medios virtuales: Destácase allí el blog La Revista Cultural Digital ICArte, que se edita desde Lima y que es un informativo cultural sobre la Región de Ica, fundada y dirigida por la gestora cultural y artista visual iqueña Cecilia Oré de Benllochpiquer. Su objetivo fundamental es noticiar sobre la cultura iqueña, sus artistas, sus personajes y todo acontecimiento cultural de trascendencia en la región.

Existen otros blogs de importancia para el cultivo de la iqueñidad. Los señalamos: La Historia de Ica, que dirige Genaro Mauricio Chanco Mendoza; Ica tierra del Sol Eterno, que dirige Arnaldo Angulo Ascama; La canción de silencio, jurachicoblogspot, que dirige Juan Ladislao Ramírez Chacaltana; y la página web del Víctor Pacheco Villar, dinámico, versado 
e iqueñísimo gestor cultural que desde hace algún tiempo viene organizando eventos de gran magnitud.

El objetivo de brindar este panorama actual como corolario de mi investigación radica en destacar el avance del aspecto cultural en Ica y esencialmente la construcción de la iqueñidad.

\section{Bibliografía}

Cabel, J. (2008). Ica en las tradiciones de Ricardo Palma. Lima: Editorial San Marcos.

Hijar Hidalgo, A. (2015). Las tradiciones de Don Ricardo Palma en la construcción de la peruanidad. En Aula Palma XIV. Lima: Universidad Ricardo Palma.

Kymlicka, W. (1996). Ciudadanía Multicultural, Ciudadanía multicultural. Barcelona: Paidós.

Palma, R. (1964). Tradiciones Peruanas completas. Madrid: Aguilar.

Paz, O. (1984). Teatro de signos. Madrid: Editorial Fundamentos, tercera edición.

Silva-Santisteban, R. (2001). Abraham Valdelomar. Obras completas. Tomo IV. Lima, Ediciones Copé.

Vásquez Ángulo, G. (1989). Pampas de Hanan y Santa Ana. Texto inédito. 